\title{
POR QUE OCUPAR? RESISTÊNCIA, CONTRACONDUTA E PROTAGONISMO ESTUDANTIL
}

\author{
José Luís Schifino Ferraro*
}

\begin{abstract}
Resumo: O presente ensaio tem como objetivo discutir o movimento de ocupações de escolas da rede pública do Brasil ocorridos no final do ano de 2015 e no início do ano de 2016 à luz da filosofia de Michel Foucault. Ao tomar como referências reportagens de jornais que acompanharam o dia a dia das ocupações - para contextualização do cenário - e da obra de Foucault para analisar tais ações protagonizadas pelos estudantes, pretendeu-se identificar elementos apontados pelo filósofo francês como importantes para o debate em torno da temática da governamentalidade. Resistência e contraconduta são dois conceitos que serão observados e discutidos ao longo desse trabalho em uma tentativa de legitimar o direito que alunos e professores têm em reivindicar uma educação pública de qualidade.
\end{abstract}

Palavras-chave: escolas; ocupação; resistência; contraconduta; protagonismo estudantil.

Resumen: Este trabajo tiene como objetivo discutir el movimiento de ocupaciones de escuelas públicas en Brasil en el final de 2015 y principios de 2016 a la luz de la filosofía de Michel Foucault. Tomando como referencias informes periódicos que siguieron el día a día de las ocupaciones - para contextualizar el escenario - y la obra de Foucault para analizar este tipo de acciones encabezadas por los estudiantes, se pretendió identificar los elementos mencionados por el filósofo francés como importantes para el debate acerca del tema de la gobernabilidad. Resistencia y contraconducta son dos conceptos que serán observados y discutidos a lo largo de este trabajo, en un intento de legitimar el derecho que estudiantes y profesores tienen de reinvindicar por una educación pública de calidad.

Palabras claves: Escuelas; ocupación; resistencia; contraconducta; protagonismo de los estudiantes.

\section{Um breve cenário das ocupações}

Não é de hoje que a educação básica no Brasil vem sofrendo com poucos investimentos. A falta de professores, os baixos salários, os problemas de infraestrutura que acometem as escolas, a redução de verbas orçamentárias das secretarias de educação $e$ a ausência de políticas curriculares sólidas no país, são alguns dos graves problemas que podem ser diagnosticados quando tratamos de analisar a realidade da rede pública de ensino.

\footnotetext{
* Professor da Faculdade de Biociências e do Programa de Pós-Graduação em Educação em Ciências e Matemática da Pontifícia Universidade Católica do Rio Grande do Sul - jose.luis@pucrs.br
}

Frente a essa realidade, ir ao encontro "da" causa para a falência da educação pública no Brasil é impossível, visto que o esquadrinhamento desse problema só poderia ser realizado a partir de uma perspectiva multifatorial. $\mathrm{O}$ mesmo ocorre em relação à sua tentativa de compreensão, pois seria preciso que considerássemos uma série de efeitos que dizem respeito às múltiplas realidades das próprias escolas - e das tentativas de implantação de políticas educacionais, principalmente curriculares - em sua relação com as coisas dos governos.

Com isso, percebe-se que ao tratarmos desse tema, invariavelmente a pauta não poderia ser outra senão - antes, neste caso - a da governabilidade. A tentativa de com- 
preensão dos acontecimentos atuais referentes ao movimento grevista impulsionado por decisões de sindicatos de professores passa também pelo apoio que a classe vem recebendo dos movimentos organizados de estudantes secundaristas, que há algum tempo, instituiu uma prática de sublevação $e$ resistência que consiste na ocupação de suas escolas.

Mas, o que significa essa ocupação? Como funciona essa organização para a ocupação? Qual a relação disso com as formas de governo? Para que possamos responder e discutir essas questões é preciso que entendamos um pouco sobre como essa prática veio à tona e tem se tornado símbolo da resistência estudantil brasileira nos últimos tempos.

A história recente da onda de ocupações de escolas no país teve seu início em São Paulo quando a secretaria estadual de educação, junto ao governo do estado, decidiu implantar uma nova política de reorganização cujo impacto indireto recairia sobre aproximadamente um milhão de alunos da rede estadual - principalmente com os casos de enturmação, que afetam também os não transferidos - (ROSSI, 2015a), e diretamente trezentos mil que seriam realocados para outras unidades de ensino (ALESSI, 2015). Com as modificações planejadas pela gestão as escolas passariam a ter ciclo único, ou seja, só ensino fundamental ou só ensino médio, o que acarretaria o remanejamento dos alunos para outras escolas, alterando seus trajetos e a organização das famílias. A justificativa dada pelo governo foi a de que escolas que comportam ciclo único tendem a ter um maior desempenho em termos educacionais atribuí- do ao melhor rendimento de seus alunos (ROSSI, 2015b).

O fato é que o remanejamento também implicaria no fechamento de escolas, o que diminuiria os custos do governo paulista com educação. A previsão era de que 94 escolas da rede estadual de São Paulo seriam fechadas e teriam, de acordo com o governo, seus prédios cedidos para outras atividades educacionais (ALESSI, 2015). A falta de diálogo entre o governo e a comunidade escolar foi apontado como uma das principais causas que motivou o movimento de ocupação, apoiado não apenas pelos professores, mas também por algumas famílias (ROSSI 2015a) (ROSSI 2015b).

Com o aumento do apoio às ocupações e pela repercussão negativa ao governo do estado, o governador de São Paulo, junto ao seu secretário de educação, decidiu voltar atrás quanto a implantação da política do remanejo prometendo um aprofundamento do debate. Mesmo assim, ainda por alguns dias, estudantes continuaram ocupando algumas escolas (SCOLESE, 2015; BOCCHINI, 2015). Com isso, a rotina criada pelos jovens - que ia desde aulas, oficinas até mesmo atividades relacionadas à manutenção, à conservação e à segurança do espaço escolar - também foi mantida. Em tais atividades ainda estão incluídas a organização para alimentação com a gestão do refeitório e horário para atendimento da imprensa (MELLO, 2015).

Pode-se dizer que o movimento de ocupação ocorrido em São Paulo no ano de 2015 foi, então, um divisor de águas que alterou a forma de reinvindicação de direitos quando se trata de discutir educação no país. No ano de 2016, escolas de São Paulo 
voltariam a ser ocupadas assim como no Rio de Janeiro, Goiás e Rio Grande do Sul. Juntos, estudantes e professores pedem o respeito aos seus direitos sob a forma de uma educação pública de qualidade. A principal exigência ainda é a melhoria nas escolas, o aumento da distribuição de livros didáticos e a valorização em termos salariais e de condições de trabalho dos professores (ARAÚJO, 2016; MARTÍN, 2016a).

No Rio de Janeiro, 65 escolas foram ocupadas. Entre março e abril de 2016, cinquenta mil alunos ficaram sem aulas e $80 \%$ dos professores aderiram a greve (MARTÍN, 2016a). Em Goiás, em menos de três semanas, doze escolas foram ocupadas. Logo em seguida a onda de ocupações aumentou este número para vinte e quatro escolas, sendo onze na capital e nove em Anápolis, os maiores centros das atividades de ocupação no estado. (MARTín, 2016b). No Rio Grande do Sul, o foco das reinvindicações foi a falta de professores e problemas de infraestrutura dos prédios escolares (FARINA, 2016). No Paraná, a qualidade de ensino e a falta de merenda escolar foram pautas para a decisão que conduziu ao processo de ocupação (DE OLIVEIRA, 2016).

A partir desse breve cenário construído sobre uma ação de protagonismo estudantil no país - ou seja, a organização dos movimentos de ocupação das escolas no Brasil - o que se pretende, agora é discuti-lo à luz da filosofia de Michel Foucault. Ao discutir o tema para identificar elementos apontados pelo filósofo francês como importantes na compreensão do debate em torno da temática da governamentalidade principalmente no que tange aos conceitos de resistência e contraconduta -, esse traba- lho também quer fazer ver as ocupações como campo de lutas e possibilidade de legitimação do direito que alunos e professores têm em reivindicar uma educação pública de qualidade.

\section{Foucault $e$ a governamentalidade: um pa- norama geral}

Para empreender uma discussão que estabeleça uma relação entre os movimentos de ocupação das escolas da rede pública e a perspectiva de Michel Foucault acerca da governamentalidade, faz-se necessário reconstruir o cenário que permitiu ao autor esboçar uma genealogia das formas de governo. Foucault foi remetido a estudar as questões sobre governo a partir da identificação e análise do que chamou de dispositivos de segurança (FOUCAULT, 2006a, p.281). O autor entende por dispositivo de segurança aquilo que possibilita inserir eventos que ocorrem em uma população "numa série de acontecimentos prováveis".

Judith Revel (2011) em seu Dicionário Foucault apresenta a noção de dispositivo como sendo "um operador material do poder". Ou seja, para a autora, segundo Foucault, os dispositivos são "técnicas, estratégias e formas de assujeitar desenvolvidos pelo poder" que podem ser, por exemplo, discursos, práticas e táticas (REVEL, 2011, p.43).

Tomando, então, como ponto de partida a análise dos dispositivos de segurança a partir da emergência da população, Foucault vai observar eventos que nela geralmente ocorrem - como o roubo, por exemplo - não na perspectiva do binário permitido/proibido, mas estabelecendo uma média. Assim o governante passará a fazer a gestão 
de ocorrências na população - como a do próprio roubo - estipulando e tentando enquadrá-lo dentro de limites aceitáveis (FOUCAULT, 2008a, p.9).

Eis a noção de governamentalidade, um saber sobre o governo que se constitui a partir de saberes sobre a população, fazendo-a aparecer como objetivo último do governo (FOUCAULT, 2008a, p.300). Em outras palavras, a governamentalidade pode ser debatida a partir da análise sobre como os dispositivos de segurança resultam em biopolíticas específicas cujo alvo é a população. Segundo Foucault, a biopolítica diz respeito "a maneira como se procurou, desde o século XVIII, racionalizar os problemas postos a prática govemamental pelos fenômenos próprios de um conjunto de viventes constituídos em população: saúde, higiene, natalidade, longevidade, raças..." (FOUCAULT, 2008b, p.431).

Foucault observa que a governamentalidade rompe com a prática da soberania. Ao longo do século XVI a questão de "como governar a si mesmo" que faz a vir à tona a problemática do governo (FOUCAULT, 2006a, p.281). As questões sobre "como governar-se, como ser governado, como governar os outros, por quem devemos aceitar ser governados, como fazer para ser o melhor governante possível" está na centralidade daquilo que o autor se propõe a estudar: seja o governo de si, o governo das almas, o governo das crianças, o governo dos príncipes ou qualquer outra forma de governo (FOUCAULT, 2006a, p.281 - 282).

Ainda, durante o século XVI, com o desfalecimento do feudalismo e o início da estruturação estatal juntamente com a ocorrência dos movimentos de reforma e con- trarreforma - questionando os modos de direção espiritual - o problema do governo evidencia-se e começa a ser concebido em sua forma política (FOUCAULT, 2006a, p.282). Observa-se tal discussão, inclusive, na literatura com "O Príncipe", de Maquiavel. A série de conselhos apresentados ao príncipe é tratada como um conjunto de habilidades as quais ele deve lançar mão para manter seu principado. Ao dispor de um laço sintético em relação ao seu território, que pode ser da ordem da tradição, da herança, da conquista ou do acordo, o príncipe deve manter seu principado por meio das relações que estabelece com seus súditos: eis a arte de governar (FOUCAULT, 2006a, p.285).

Sobre as múltiplas formas de governo que sempre existiram, mas que floresceram principalmente nesta época e a questão do príncipe, Foucault ressalta que "[...] muitas pessoas governam: o pai de família, o superior de um convento, o pedagogo e o professor com a relação com a criança ou com o discípulo", inclusive o príncipe, que nada mais faz do que exercer uma dentre tantas modalidades de governo. No entanto, sobre tais modalidades de governo, enfatiza que sempre são interiores à sociedade ou ao Estado (FOUCAULT, 2006a, p.286).

Considerando as questões relacionadas ao governo, o filósofo francês ainda discute suas possibilidades em três dimensões bem definidas, a saber: a moral, a economia e a política. Tais dimensões representam, respectivamente, o governo de si, a arte de governar a família e a ciência de bem governar o Estado (FOUCAULT, 2006a, p.287). Se observamos em uma perspectiva descendente essas dimensões, do governo 
do Estado (política), passando pelo governo da família (economia, em sua acepção etimológica), até o governo de si (moral, em um nível individual) faz aparecer a necessidade de constituição da polícia para vigilância e controle da população. O fato é que analisando a governamentalidade em qualquer um desses níveis, a ideia quer permanece e se apresenta é sempre a mesma: a da gestão (FOUCAULT, 2006a, p.288-289).

Governar um Estado será, então, lançar mão da economia, uma economia no nível do Estado todo, quer dizer, ter para com os habitantes, as riquezas, a conduta de todos e de cada um uma forma de vigilância e de controle, não menos atenta do que a do pai de família para com os familiares e seus bens (FOUCAULT, 2006a, p.289)

Com isso, evidencia-se que a economia que no século XVI aparece como forma de governo (a economia política), ao longo do tempo - e principalmente durante o século XVIII - aparecerá como campo de intervenção (FOUCAULT, 2006a, p.289).

Numa palavra, pode-se dizer que a nova governamentalidade que, no século XVII, tinha acreditado poder aplicar-se inteira num projeto exaustivo e unitário de polícia, vê-se agora numa situação tal que, de um lado, terá de se referir a um domínio de naturalidade que é a economia. Terá de administrar populações (FOUCAULT, 2008a, p.476).

Em uma perspectiva em que o governo passa a dar conta da disposição das coisas, ou seja, sua finalidade está nas coisas que ele dirige, pode-se pensar na economia como campo de intervenção em nome da manutenção de uma razão de Estado cuja finalidade é o bem-estar, o bem gerir a po- pulação (FOUCAULT, 2006a, p.289-293). Logo, a coisa pela qual o governo se encarrega é a população, mais especificamente as pessoas em suas relações com "as riquezas, os recursos, as substâncias, o território [...] seu clima, sua aridez, sua fertilidade [...] os costumes, os hábitos, as maneiras de fazer ou pensar [...] os acidentes, as desgraças, como a fome, as epidemias e a morte" (FOUCAULT, 2006a, p.290).

Observa-se, então, que a arte de governar é impulsionada com a emergência da população, pois a estatística, o cálculo de indicadores, a quantificação de fenômenos, começam a ser utilizados para a gestão dessa população e, portanto, voltados a ela (FOUCAULT, 2006a, p.298-299). A família também passa a exercer um papel fundamental e central no governo da população, pois torna-se o instrumento de inculcação de valores e comportamentos desejáveis (FOUCAULT, 2006a, p.299). A ordem disciplinar também é mantida, principalmente no interior de instituições que contribuem para a arte de governar e para a governamentalização do Estado (FOUCAULT, 2006a, p.302-304).

Ao construir esse breve cenário para discussão em torno dos movimentos de ocupações das escolas ocorridas no Brasil no final do ano de 2015 e no início do ano de 2016 sob a perspectiva foucaultiana da governamentalidade, foi preciso resgatar elementos que conduziram Foucault a observá-la como um campo de produção de saberes sobre a população - $e$, consequentemente sobre o Estado - a partir da análise dos dispositivos de segurança. A partir de agora o objetivo deste ensaio será o de aproximar a ideia de contraconduta propos- 
ta por Foucault da ação estudantil como resistência durante o período de ocupação das escolas.

\section{Governamento, Resistência e Contra- conduta}

Para que o presente texto possa avançar nessa discussão sobre os movimentos de ocupação das escolas públicas brasileiras, além de olhar para a resistência estudantil na perspectiva de uma contraconduta - e após discutirmos e observamos a questão da governamentalidade em Foucault regendo e (re)dimensionando o conteúdo da escrita dessas linhas - é preciso explorar um pouco mais a questão do governamento.

Em seu texto "Resposta à pergunta: o que é a Ilustração?' (KANT, 1974), o filósofo Immanuel Kant propõe o uso da razão como elemento fundamental para que a humanidade possa abandonar seu estado de minoridade. Kant, ao mesmo tempo em que aponta tal necessidade, faz um debate sobre a impossibilidade de não sermos governados (KANT, 1974, p.1). Em assim sendo, segundo o próprio autor, a minoridade que acomete o ser humano diz respeito a sua "incapacidade de servir-se de seu entendimento sem a tutela de outro" (KANT, 1974, p.1). Para Kant, a prerrogativa do sapere aude é essencial para que a humanidade vá em busca do esclarecimento (KANT, 1974, p.1), mas mesmo assim mesmo que o homem se esforce para abandonar sua "condição menor", não conseguirá libertar-se do jugo de ser governado por outrem, por leis, etc.

Se possuo um livro que possui entendimento por mim, um diretor espiritual que possui consciência em meu lugar, um médico que decida acerca de meu regime, etc., não preciso eu mesmo esforçar-me. Não sou obrigado a refletir, se é suficiente pagar; outros se encarregarão por mim da aborrecida tarefa (KANT, 1974, p.1-2).

Kant trata de uma questão fundamental - a do governo - que, mais tarde terá sua dimensão ampliada e debate aprofundado por Michel Foucault. Ao estudar as formas pelas quais o indivíduo se produz e reconhece como sujeito $e$ as relações de poder imbricadas nesse processo de constituição, Foucault começa a delimitar a governamentalidade como campo de produção de saberes relacionadas às práticas de governamento de si e dos outros (FOUCAULT, 2009).

Ao travar um debate sobre o governamento, aponta, ainda, a perspectiva do cuidado de si (epiméleia heautou) como extensão a prática da governamentalidade (FOUCAULT, 2006b; FOUCAULT 2008a).

(...) o governo pôs-se a também querer se encarregar da conduta dos homens, a querer conduzi-los, a partir desse momento vamos ver que os conflitos de conduta já não vão se produzir tanto do lado da instituição religiosa, e sim, muito mais, do lado das instituições políticas. E vamos ter conflitos de conduta nos confins, nas margens da instituição política (FOUCAULT, 2008a, p.261).

No caso das instituições de ensino - $e$ aqui se trata de discutir as escolas não apenas como palco das ocupações, mas também como agentes de assujeitamento e subjetivação -, uma das formas como o governo das condutas é realizado dá-se por meio de um currículo que intenta promover possibilidades de experienciação essenciais à (trans)formação de si. Cabe, então, considerar que a promoção dessa (trans)formação 
que leva em conta os processos de subjetivação, passa por uma dimensão que é da experiência. Em assim sendo a temática curricular ganha força se considerarmos as diversas orientações, práticas e ações que os currículos podem fazer recair sobre os corpos como territórios a serem disciplinados, docilizados (VEIGA-NETO, 2002) ou ainda governados (PEREIRA; FERRARO, 2011).

Em "A hermenêutica do sujeito", Foucault empreende um trabalho que vai analisar como, no Ocidente, se tramaram as relações entre o "sujeito" e a "verdade" (FOUCAULT, 2006b, p.4). Neste sentido o que se observa é uma mudança de direção naquilo que o próprio autor tinha como foco de estudo, marca do pensamento foucaultiano. Houve um deslocamento, ou se preferirmos, um acréscimo às questões concernentes ao saber-poder corporificado a partir do que se pode verificar como sendo o estudo da constituição do sujeito.

Como o próprio Foucault afirma, seu "ponto de partida" é uma "noção" do que vem a ser o cuidado de si (FOUCAULT, 2006b, p.4). O cuidado de si tomado como "princípio de agitação", de "movimento", de "permanente inquietude no curso da existência" (FOUCAULT, 2006b, p.11) que parte de "um certo modo de encarar as coisas, de estar no mundo, de praticar ações, de ter relações com o outro. A epiméleia heautou é uma atitude - para consigo, para com os outros, para com o mundo" (FOUCAULT, 2006b, p.14).

Foucault, então delimita a amplitude, dimensionando as implicações do cuidado de si.

Cuidar de si mesmo implica que se converta o olhar, que se o conduza do exterior para... eu ia dizer "o interior"; deixemos de lado esta palavra (que, como sabemos, coloca muitos problemas) e digamos simplesmente que é preciso converter o olhar, do exterior, dos outros, do mundo, etc. para si mesmo" (FOUCAULT, 2006b, p.14).

Portanto, há no cuidado de si algo que deve ser interiorizado, de um mundo que está posto em direção ao interior do indivíduo. É nesse movimento de interiorização que o indivíduo se subjetiva, ou seja: podemos estabelecer a partir da elaboração de práticas, técnicas ou até mesmo de uma "arte de viver" (tékhne tôu bíou) olhando para si, o cuidado de si em relação com a emergência de um sujeito - sempre inacabado -, um indivíduo que está no mundo faz escolhas e tem determinados posicionamentos.

A pergunta - "como fazer para viver como se deve?" - era a pergunta da tékhne tôu bíou: qual é o saber que me possibilitará viver como devo viver, como devo viver enquanto indivíduo, enquanto cidadão, etc.? Esta pergunta ("como fazer para viver como convém?") tornar-se-á cada vez mais idêntica ou cada vez mais nitidamente incorporada à pergunta: "como fazer para que o eu se tome e permaneça aquilo que ele deve ser?" (FOUCAULT, 2006b, p.219).

Mas ao que de fato nos conduz esta tékhne tou bíou? A resposta está no próprio cuidado de si, na interiorização de elementos que dão conta em uma dimensão aquisitiva, de equipar-se, de pegar para si uma série de ações práticas que derivam de discursos que são exteriores ao próprio indivíduo e que - de certa forma - corresponde ao movimento de transição indivíduo/sujeito 
passando a compor seus novos modos de existência (subjetivação).

(...) o cuidado de si, que aparecia no interior do princípio ou tema geral de que devemos nos propiciar uma tékhne (uma arte de viver), ocupou de certo modo todo o lugar definido pela tékhne tou bíou. O que os gregos procuravam nestas técnicas de vida, sob formas muito diferentes durante tantos séculos, desde o começo da idade clássica, a saber, a tékhne tou bíou, é agora, neste gênero de pensamento, ocupada inteiramente pelo princípio de que é preciso cuidar de si, cuidar de si que é equipar-se para uma série de acontecimentos imprevistos, em relação aos quais, porém serão praticados alguns exercícios que os atualizam como uma necessidade inevitável, em que serão despojados de tudo que possam ter de realidade imaginária, a fim de reduzi-los estritamente ao mínimo de sua existência (FOUCAULT, 2006, p.588-589).

Porém, em Foucault é a dimensão do cuidado de si é ampliada. O autor, ainda, vai além fazendo um paralelo com a questão da governamentalidade.

Como vemos, "ocupar-se consigo" está, porém, implicado na vontade do indivíduo de exercer o poder político sobre os outros e dela decorre. Não se pode governar os outros, não se pode bem governar os outros, não se pode transformar os próprios privilégios em ação política sobre os outros, em ação racional, se não se está ocupado consigo mesmo. Entre privilégio e ação política, este é, portanto, o ponto de emergência da noção de cuidado de si (FOUCAULT, 2006b, p.48).

Aqui, temos dois temas relevantes essenciais à questão curricular e, portanto, à própria escola. Um deles diz respeito a subjetivação ampliada pelo cuidado ou experiência de si, o outro deles vai ao encontro com algo que é natural do próprio currículo tomado como discurso, ou seja, são as relações de governamento, a governamentalidade. Veiga-Neto e Lopes (2007) fazem uma distinção:

A partir desses entendimentos, parece-nos mais apropriado usarmos a palavra governamento, e não governo, para designar todo o conjunto de ações de poder que objetivam conduzir (governar) deliberadamente a própria conduta ou a conduta dos outros ou, em outras palavras, "que visam estruturar o eventual campo de ação dos outros". Com isso, deixamos a palavra governo para designar tudo o que diz respeito às instâncias centralizadoras do Estado e usamos governamento para designar todo o conjunto das ações - dispersadas, disseminadas e microfísicas do poder que objetivam conduzir ou estruturar as ações (VEIGA-NETO; LOPES, 2007, p.952).

Para Foucault o que está implicado nas relações de governamento é o próprio poder:

(...) entendido como uma ação sobre ações possíveis - uma ação sempre escorada em saberes -, o governamento manifesta-se quase como um resultado dessa ação; na medida em que alguém coloca em funcionamento o poder sobre outrem, esse alguém pode governar esse outrem. Pode-se dizer então que, de certa maneira, o governamento é a manifestação "visível", "material", do poder (VEIGA-NETO; LOPES, 2007, p.952-953).

O sujeito, segundo Foucault é constituído na trama dos discursos, o que significa dizer ao mesmo tempo em que isto ocorre em meio a relações de poder e, portanto, também em meio a relações de governamento. A condição para governar-se é cuidar de si, experimentar-se para que haja 
posicionamento em termos de ações e práticas. O mesmo vale para governar os outros. Em assim sendo, em Foucault o sujeito pode ser observado a partir de eixos como objetivação (enquanto sujeito do conhecimento), individuação e subjetivação, estas últimas relacionadas à relação do sujeito com aquilo que lhe é exterior (mecanismos coercitivos) e consigo mesmo, de maneira espontânea (HACK, 2006).

Uma das formas de governamento estudadas por Foucault é o pastorado ou poder pastoral. Foi a partir do estudo do pastorado que o filósofo desenvolveu a noção de conduta: o pastor como condutor das almas pela "vereda da salvação e da verdade" (FOUCAULT, 2008a, p.222). Por outro lado, a noção de contraconduta também é explorada pelo autor (FOUCAULT, 2008a, p.255). Ao esboçar um panorama histórico relacionado às formas de governamentalidade, ele justifica sua escolha pelo termo contraconduta. Segundo o autor, no cristianismo, o pastorado foi responsável pelo estabelecimento de toda "uma arte de conduzir, de dirigir, de levar, de guiar, de controlar, de manipular os homens" encarregando-se de cada um deles "coletiva $e$ individualmente ao longo de toda a vida deles e a cada passo da sua existência" (FOUCAULT, 2008a, p.218-219).

Foucault faz uma ressalva sobre o pastorado no sentido de que não se trata de uma política, uma pedagogia ou retórica, mas de uma forma de governar os homens que possui relação com o nascimento do Estado Moderno, pois é exatamente quando essa governamentalidade "se torna efetivamente uma forma política calculada e refletida" - principalmente no período compre- endido entre o final do século XVI e o século XVIII - é que sua constituição pode ser percebida (FOUCAULTa, p. 219). Há uma relação direta entre o pastorado - cristão - $e$ as leis que pode ser observada a partir da instituição da obediência. A obediência como "tipo de conduta unitária" (FOUCAULTa, 2008, p. 230). Na medida em que há uma transformação na maneira de se governar - do território à população -, é que surgem inúmeras práticas - biopolíticas voltadas ao cuidado dessa população que passam a ser atribuídas como função do Estado.

Para Foucault a conduta diz respeito à condução das conduções, "a maneira como se deixa conduzir, a maneira como é conduzida e como, afinal de contas, ela se comporta sob o efeito de uma conduta que seria o ato de conduta ou de condução" (FOUCAULT, 2008a, p. 255). O autor mostra como a crise do pastorado possibilitou a emergência da "dimensão da governamentalidade" ou "como o problema do governo, da governamentalidade pode se colocar a partir do pastorado" (FOUCAULT, 2008a, p.255).

\section{As ocupações como forma contraconduta}

Ao esboçar um panorama geral sobre as questões relacionadas a governamentalidade e a origem da expressão contraconduta em Michel Foucault, é preciso agora aproximar os elementos dessa discussão à questão das ocupações. Primeiramente devemos começar respondendo algumas questões que foram propostas no início dessas linhas, sempre tendo como parâmetro $e$ referência elementos subsidiários à discussão que foram apresentados até aqui. 
A primeira pergunta diz respeito ao possível significado dessa ocupação. Para respondê-la, em primeiro lugar, deve-se olhar para a escola como o lugar onde são (re)produzidas situações recorrentes do contexto social. Nesse sentido, todas as relações sociais - principalmente no que tange às relações de saber-poder e governamento podem ser evidenciadas na escola. Assim como a governamentalidade colocou pela primeira vez a população como "problema político", objeto construído pela gestão política global dos indivíduos - pelas biopolíticas - (REVEL, 2011, p.75), temos a materialização dessa objetivação quando se observa a população de alunos em relação a de professores, e a de professores em relação a coordenadores, supervisores e/ou diretores. Essas relações são de poder (biopoder), constituem-se em políticas, um conjunto de práticas e estratégias que indivíduos tem em relação a si mesmos e aos outros.

Segundo Edgardo Castro (2014, p. 103) o biopoder é diferente do "poder soberano", pois age de maneira positiva sobre a vida, administrando-a no sentindo de potencializar suas forças em "um campo de valor e utilidade". As relações de governamento na escola, são relações de biopodere disso, emergem micropolíticas, práticas voltadas à gestão das populações. Em uma tentativa de tentar se compreender qual o possível significado das ocupações - não os motivos, pois esses bem se conhecem e já foram explorados na parte inicial do texto -, percebe-se uma não aceitação por parte dos estudantes à forma como a educação, e, portanto, os próprios alunos e professores, estavam sendo governados por instâncias de governo politicamente instituído, a saber, os governos estaduais.

Se quando se governa "se põem em marcha um conjunto de ações sobre ações possíveis" (CASTRO, 2014, p.112), se a governamentalidade pode ser entendida como um "conjunto de práticas que funcionam como dispositivos de segurança pelo meio das quais se governa a população" (CASTRO, 2014, p.122), fica claro que na visão dos estudantes era necessária e urgente a mudança de atitude do estado em relação às coisas da educação estendendo-se para as formas de governamento das pessoas envolvidas. Eis o que justifica os movimentos de sublevação e resistência e a ocupação como prática de contraconduta.

Com relação à questão sobre a organização para as ocupações, os estudantes perceberam a necessidade de governarem-se a si mesmos ao dividirem tarefas para manutenção do funcionamento "informal" da escola e estipularem horários de oficinas que contemplavam os mais diferentes conteúdos não necessariamente alinhados ao rigor e a sequência das disciplinas integrantes das matrizes curriculares. Outros tópicos passaram a integrar suas atividades diárias, como oficinas de educação popular ambiental, debates sobre gênero e sexualidade, artesanato, malabares entre outras. Ainda, um conjunto de regras de conduta - diferente das prescrições normativas oficiais até então vigentes - foram estabelecidas, o que foi fundamental para dar certa unidade ao movimento que se então se alastrava pelos estados brasileiros.

Logo, ao observarmos tudo isso, pode se perceber uma direta relação do movimento de ocupação com as relações de go- 
vernamento, com a governamentalidade colocadas por Foucault. Para o autor, não há governo sem produção de verdade, sem jogos de verdade que correspondem a procedimentos e regras que permitem distinguir o verdadeiro do falso, que estabelecem formas de veridicção o que acaba por definir um ethos, a partir do momento em que, dependendo das relações e formas de governamento, indivíduos podem produzir verdade sobre si, ou ainda produzirem-se a si mesmos tendo suas próprias vidas como forma de verdade (CASTRO, 2014, p.123).

As ocupações como contraconduta também produziram um efeito interessante no sentido de nos conduzir a um tipo de pensamento crítico que interroga o regime de verdade que produzido, ou os tipos de possibilidade de veridicção que estavam sendo avalizados por governos que há alguns anos tem olhado a educação como prioridade menor em nosso país. Os secundaristas que estiveram à frente dos movimentos de ocupação ao aderirem à resistência estudantil inseriram-se em um grupo que fez ver à sociedade outras possibilidades, formas e práticas de governamento que colocam à escola, seus profissionais - à comunidade escolar como um todo - no centro da discussão sobre a valorização da educação.

Ao realizarem as ocupações sob a perspectiva do exercício da resistência os estudantes reafirmaram a sua vontade e a necessidade urgente de se repensar a educação como um todo. Nesse movimento afirmativo, se empoderaram ao pautarem suas reinvindicações em face aos acontecimentos políticos cuja interferência recairia de forma direta sobre os modos de condução da edu- cação no Brasil, como o PL 44/2016 no proposto no Rio Grande do Sul que permitiria a transformação de empresas públicas, fundações, entre outras, ligadas ao ensino, à pesquisa científica, ao desenvolvimento tecnológico, à gestão, proteção e preservação do meio ambiente, à ação social, ao esporte, à saúde e à cultura em organizações sociais (RIO GRANDE DO SUL, 2016).

A partir do que foi colocado, percebe-se que o debate sobre as ocupações é uma questão de ordem política que, claramente, poder ser circunscrita na discussão em torno da governamentalidade. De um lado, o governo dos estados que tiveram suas escolas ocupadas tentando administrar - cada um à sua forma, muitos inclusive se negando a negociar como estratégia de pressionar o movimento de resistência - a população e gerir o problema. Por outro lado, jovens estudantes apoiados pelos professores grevistas, familiares e movimentos sindicais, bem como outros setores da sociedade, que consideravam legítimas as reinvindicações.

Percebe-se que no centro da organização dessa resistência, além, obviamente, das questões concernentes ao poder, encontrase a possibilidade de uma resposta ativa à pergunta "como fazer para viver como se deve?", relacionada à já referida premissa do tékhne tôu bíou. Para viver como se deve. Uma "arte de viver". Há sempre um modelo paradigmático de sociedade, há sempre uma vontade, uma crítica ou um juízo de valor por trás do "como se deve" em relação a um status quo vigente. Nesse contexto, as ocupações como forma de contraconduta também poderiam ser observadas como atitude - epimeléia heautou - 
frente ao mundo, uma resposta desses estudantes para o colapso da educação no país.

Pois bem, fica claro que a contraconduta não foi observada apenas no movimentode sublevação estudantil em si que fechou as escolas e impediu a entrada de representantes do estado como a polícia. O que esteve em jogo todo o tempo foi, também, a crítica aos modos como escolas e o sistema educacional brasileiro estão organizados $e$ estruturados, à forma como estão sendo geridos e aos parcos investimentos que estão sendo feitos.

Há claramente um conflito de concepções em torno do modelo de escolarização no país, onde um vai de encontro ao outro. Desse choque emergem, nada mais nada menos que percepções ideológicas, vontades, tensões pautadas pelo tensionamento das relações de poder e enfrentamento. São distintas visões interessadas sobre educação $e$, talvez, ambas almejassem como destino final - e cada uma a sua forma - a valorização dos profissionais envolvidos, passando por melhorias nas condições pelas quais os alunos são submetidos uma vez inseridos nos Ensinos Fundamental e/ou Médio.

Tomando exatamente como referência a polarização governos estaduais/resistência estudantil e o desejo - visão de sociedade/educação - das partes envolvidas, deveríamos nos perguntar: afinal, seriam estes modelos de escola tão diferentes entre si? Ou seriam estas concepções de mundo $e$ formação diferentes entre si a ponto de idealizarmos distintas relações e modos de funcionamento envolvendo a gestão da educação e portanto os modos de se (re)pensar a escola?

$\mathrm{O}$ que fica desses movimentos de ocupação, não é apenas uma tentativa de autogestão ou autogovernamento. Pensar assim seria reduzi-los. O que realmente empreendeu-se foi a vontade e o desejo de se fazer ver e ouvir. Ainda, mais do que isso, o que está em jogo é a emergência de novas formas e práticas, não de protestar, simplesmente, mas para aquisição de uma nova/outra postura, um novo/outro comportamento relacionado aos modos como os sujeitos podem e devem reivindicar seus direitos engajando-se de maneira mais comprometida ao tomarem para si a coisa pública, as coisas do estado.

Inegavelmente este novo ethos produziu a ocupação como mais um campo de lutas e disputas na sociedade contemporânea, o que vem a estreitar os laços da relação entre a ética e a governamentalidade evidenciando que toda prática de governo além de estar vinculada a um ideário de liberdade, também é sempre orientada por uma crença ou percepção que emerge das formas como os indivíduos se governam $e$ se subjetivam, incorporando $e$ (res)significando elementos discursivos exteriores, inaugurando constantemente outros olhares para se ver - e outras condutas para se estar - (n)o mundo.

\section{Referências}


ALESSI, Gil. Por que a reforma que afeta 300.000 alunos em SP virou caso de polícia?: para especialistas, falta de planejamento do governo estadual agravou a crise. El País, Brasil, versão online, 14 nov. 2015. Acesso em: 19 mai. 2016. Disponível em: http://brasil.elpais.com/brasil/2015/11/13/politica/1447426542 534410.html.

ARAÚJO, Hugo. "Não queremos nossa escola tratada como sucata", diz estudante de ocupação. UOL Educação, Brasil, 5 mai. 2016. Acesso em: 20 mai 2016. Disponível em: http://educacao.uol.com.br/noticias/2016/05/04/nao-queremos-nossa-escola-tratada-comosucata-diz-estudante-de-ocupacao.htm.

BOCCHINI, Bruno. Após um mês de ocupação das escolas, estudantes de SP continuam nas ruas. Agência Brasil, Brasil, versão online, 9 dez 2015. Acesso em 21 mai. 2016. Disponível em: http://agenciabrasil.ebc.com.br/geral/noticia/2015-12/apos-um-mes-de-ocupacao-dasescolas-estudantes-de-sp-continuam-nas-ruas.

BORGES, Fernanda. Secretaria divulga chamamento de OSs para gerir escolas em Goiás: edital com requisitos foi publicado no Diário Oficial e está no site da Seduce. Apesar de protestos de alunos, é ofertada a administração de 23 escolas. G1, Brasil, 6 jan. 2016. Acesso em: 20 mai. 2016. Disponível em: http://g1.globo.com/goias/noticia/2016/01/secretaria-divulga-chamamento-de-oss-para-gerirescolas-em-goias.html.

CASTRO, Edgardo. Introdução à Foucault. Belo Horizonte: Editora Autêntica, 2014.

DE OLIVEIRA, Cida. Paraná tem primeira escola estadual ocupada por qualidade do ensino e da merenda. Rede Brasil Atual, Brasil, 18 mai. 2016. Acesso em 20 mai. 2016. Disponível em: http://www.redebrasilatual.com.br/educacao/2016/05/parana-tem-primeira-escola-estadualocupada-por-estudantes-em-defesa-de-escola-publica-de-qualidade-9093.html.

FARINA, Erik. Movimento que inspirou alunos da Capital começou em São Paulo: em Porto Alegre, quatro colégios permaneciam invadidos nesta sexta-feira. Zero Hora digital, Brasil, 13 mai. 2016. Acesso em: 20 mai.2016. Disponível em: http://zh.clicrbs.com.br/rs/vida-eestilo/noticia/2016/05/movimento-que-inspirou-alunos-da-capital-comecou-em-sao-paulo5800918.html.

FOUCAULT, Michel. Ditos e escritos, v.4. Rio de Janeiro: Forense Universitária, 2006a.

. A hermenêutica do sujeito. São Paulo: Martins Fontes, 2006 b.

. Território, segurança e população. São Paulo: Martins Fontes, 2008a. 
. Nascimento da Biopolítica. São Paulo: Martins Fontes, 2008 b.

. El gobierno de si y de los otros: curso en el Collège de France : 1982-1983. Buenos Aires : Fondo de Cultura Económica, 2009.

HACK, Rafael Fernando. Michel Foucault $e$ a individuação discursiva. Tempo da Ciência, v. 13, n. 26, p. 25-38, 2006 25-38.

KANT, Immanuel. Resposta à pergunta: que é esclarecimento. Textos seletos, v. 3, 1974. Acesso em: 23 mai. 2016. Disponível em: http://ensinarfilosofia.com.br/_pdfs/e livors/47.pdf.

MARTÍN, Maria. Escolas ocupadas já são 65 no Rio e Estado enfrenta impasse na negociação: governo reconhece ter entrado em beco sem saída e jovens contra ocupação cobram protagonismo. El País, Brasil, 2 mai. 2016a. Acesso em 20 mai. 2016. Disponível em: http://brasil.elpais.com/brasil/2016/04/29/politica/1461955632_442061.html.

. Inspirados em SP, colégios estaduais do Rio vivem onda de ocupações: no meio de uma greve de professores, alunos tomam pelo menos 12 escolas. El País, Brasil, 8 abr. 2016b. Acesso em 20 mai. 2016. Disponível em: http://brasil.elpais.com/brasil/2016/04/08/politica/1460123788_119886.html.

MENDONÇA, Renata. Alckmin recua em fechamento de escolas em SP: para onde vai o movimento dos estudantes agora. $B B C$, Brasil, versão online, 4 dez. 2015. Acesso em: 19 mai. 2016.

Disponível

em:

http://www.bbc.com/portuguese/noticias/2015/12/151204_alckimin_estudantes_movimento_r $\underline{\mathrm{m}}$.

MELLO, Daniel. Em escolas ocupadas em SP, rotina de alunos inclui limpeza e aulas abertas. Agência Brasil, Brasil, 25 nov. 2015. Acesso em: 23 mai. 2016. Disponível em: http://agenciabrasil.ebc.com.br/educacao/noticia/2015-11/estudantes-se-esforcam-paramanter-atividades-em-escolas-ocupadas-em-sao.

ROSSI, Marina. Ocupação de 182 escolas em SP vira teste de resistência de Alckmin: governo tenta ganhar tempo sem uma estratégia de negociação clara. El País, Brasil, versão online, 28 nov. 2015a. Acesso em: 19 mai. 2016. Disponível em: http://brasil.elpais.com/brasil/2015/11/27/politica/1448630770_932542.html.

. A vida em uma escola ocupada que resiste a fechar as portas em São Paulo: reportagem de EL PAÍS entra em um dos colégios tomados em protesto contra reforma. El País, Bra- 
sil, versão online, 19 nov. 2015b. Acesso em: 19 mai. 2016. Disponível em: http://brasil.elpais.com/brasil/2015/11/18/politica/1447880834_214816.html.

SCOLESE, Eduardo. Sob protestos, Alckmin suspende plano de reorganização de escolas. Folha de São Paulo, Brasil, versão online, 4 dez. 2015. Acesso em 21 mai. 2016. Disponível em: $\quad$ http:/www1.folha.uol.com.br/educacao/2015/12/1714946-sob-protestos-alckminsuspende-plano-de-reorganizacao-de-escolas.shtml.

FOLHA DE SÃO PAULO. 'Vamos aprofundar o diálogo', diz Alckmin sobre recuo de fechamento de escolas. Folha de São Paulo, Brasil, versão online, 4 dez. 2015. Acesso em 21 mai. 2016. Disponível em: Folha de São Paulo, Brasil, versão online, $4 \mathrm{dez}$. 2015. Acesso em 21 mai. 2016. Disponível em: http://www1.folha.uol.com.br/educacao/2015/12/1714969-vamosaprofundar-o-dialogo-diz-alckmin-sobre-recuo-de-fechamento-de-escolas.shtml.

PEREIRA, Marcos Villela; FERRARO, José Luís Schifino. DE CONTROLE: o caso da gripe H1N1. Currículo sem Fronteiras, v. 11, n. 2, p. 134-146, 2011, 134-146.

REVEL, Judith. Dicionário Foucault. Rio de Janeiro: Forense Universitária, 2011.

RIO GRANDE DO SUL. Assembleia Legislativa Projeto de Lei Complementar PLC 44/2016. Dispõe sobre a qualificação de entidades como organizações sociais. Acesso em: 13 jul. 2016. Disponível em:

http://www.al.rs.gov.br/legislativo/ExibeProposicao/tabid/325/SiglaTipo/PL/NroProposicao/44/ AnoProposicao/2016/Origem/Px/Default.aspx.

VEIGA-NETO, Alfredo. De Geometrias, Currículo e Diferenças. Educação \& Sociedade, ano XIII, n' 79, agosto- 2002, 163-186.

VEIGA-NETO, Alfredo; LOPES, Maura Corcini. Inclusão e governamentalidade. Educ. Soc., Campinas , v. 28, n. 100, out. 2007, 947-963.

Recebido em: 25/08/2016 Aprovado em: 19/10/2016 